\title{
Strong specificity and network modularity at a very fine phylogenetic scale in the lichen genus Peltigera
}

\author{
P. L. Chagnon ${ }^{1}$ (1) N. Magain ${ }^{2} \cdot$ J. Miadlikowska² ${ }^{2}$ F. Lutzoni ${ }^{2}$
}

Received: 29 August 2017 / Accepted: 3 May 2018 / Published online: 14 May 2018

๑) Springer-Verlag GmbH Germany, part of Springer Nature 2018

\begin{abstract}
Identifying the drivers and evolutionary consequences of species interactions is a major goal of community ecology. Networkbased analyses can provide mathematical tools to detect non-random patterns of interactions, and potentially help predicting the consequences of such patterns on evolutionary dynamics of symbiotic systems. Here, we characterize the structure of a lichen network at a very fine phylogenetic scale, by identifying the photosynthetic partners (i.e., cyanobacteria of the genus Nostoc) of lichenized fungi belonging to a monophyletic section of a single genus (i.e., section Polydactylon of the genus Peltigera), worldwide. Even at such a fine phylogenetic scale, we found that interactions were highly modular and anti-nested, indicating strong preferences in interactions. When considering local Peltigera communities, i.e., datasets at small spatial scales with only a slightly broader phylogenetic range, interactions remained modular but were asymmetric, with generalist Nostoc partners interacting with specialized Peltigera species. This asymmetry was not detected with our global spatial scale dataset. We discuss these results in the light of lichen community assembly, and explore how such interaction patterns may influence coevolution in lichens and the evolutionary stability of the mutualism in general.
\end{abstract}

Keywords Cyanolichens $\cdot$ Partner selection $\cdot$ Mutualism $\cdot$ Nostoc $\cdot$ Symbiosis

\section{Introduction}

One fundamental goal of community ecology has typically been to determine why species occur in some places but not in others (Vellend 2016), and why some species interact preferentially. This latter line of inquiry was first applied to trophic interactions (e.g., Ulanowicz and Kemp 1979; Pimm and Lawton 1980; Ulanowicz 1986, 1997), but quickly reached mutualistic associations (e.g., Herrera 1982; Jordano 1987). During the last decade, there has been

Communicated by Joel Sachs.

Electronic supplementary material The online version of this article (https://doi.org/10.1007/s00442-018-4159-6) contains supplementary material, which is available to authorized users.

P. L. Chagnon

pierre-luc.chagnon@umontreal.ca

1 Départment des Sciences Biologiques, Institut de Recherche en Biologie Végétale, Université de Montréal, 4101 rue Sherbrooke Est, Montréal, QC H1X 2B2, Canada

2 Department of Biology, Duke University, Durham, NC 27708, USA a renewed interest in multispecies interactions in community ecology with the application of network-based tools to uncover interaction patterns (Dupont et al. 2003, 2009; Olesen et al. 2007). These tools were identified as potentially useful to (1) elucidate the assembly mechanisms responsible for such structure, and (2) determine the consequences of such patterns on community dynamics (e.g., species persistence, secondary extinctions) and on the coevolution of species (Thompson 2009).

The bulk of the studies on ecological networks has focused on plant-animal interactions (e.g., pollination, frugivory, myrmecophytic plants) (Bascompte et al. 2003; Guimarães et al. 2006; Burns 2013). In those systems, network-based approaches have contributed to highlight how interaction patterns resulted from the joint influence of species abundances (Vázquez et al. 2005), phenotypic traits (Stang et al. 2007, 2009; Donatti et al. 2011; Maglianesi et al. 2015) and evolutionary history (Rezende et al. 2007; Gómez et al. 2010). A number of network studies have also been conducted on plant-fungal symbioses, e.g., mycorrhizae (Montesinos-Navarro et al. 2012; Martos et al. 2012; Chagnon et al. 2015) and fungal endophytes (Chagnon et al. 2016). Likewise, in those systems, interaction patterns were 
shown to be structured by host traits (Kembel et al. 2014; Chagnon et al. 2015, 2016), habitat preferences (Martos et al. 2012; Torrecillas et al. 2014) or species abundances (Chagnon et al. 2015). These studies have provided insights on the establishment of mutualistic interactions between fungi and photosynthetic partners, and allowed the exploration of the similarities and differences with plant-animal networks (Toju et al. 2014). The ecologically and evolutionarily successful lichen symbiosis, involving primarily fungi (mycobionts) and photosynthetic algae and/or cyanobacteria (photobionts), still has not been characterized from a network perspective. Yet, there is a clear interest in using this symbiosis as a model system, including the possibility to pose novel hypotheses regarding interaction establishment, and maintenance of mutualism.

About one-fifth of all known species of fungi are lichenized (Feuerer and Hawksworth 2007; Kirk et al. 2008). Unlike mycorrhizae and fungal endophytes, the symbiotic unit, the lichen thallus, is visible and often distinct, which enables efficient sampling design. Moreover, in lichens, the mycobionts are often more dependent on photobionts than vice versa (Nash 2008; Lutzoni and Miadlikowska 2009). The fungal partner forming the thallus (the mycobiont) cannot live independently from its photobiont unless a loss of lichenization is at play in a specific fungal clade (Lutzoni et al. 2001; Wedin et al. 2004). This could lead us to expect that specialization is rarely reciprocal in this symbiosis: if mycobionts are so dependent upon compatible photobionts, then there must be a pressure to remain generalist and broadly compatible with many photobionts, as any compatible partner is better than none. However, if these associations with various photobionts result in a range of fitness levels for the mycobiont, natural selection could lead to the specialization of a fungal species on a few optimal photobionts. If some of these photobionts are advantageous to many closely related lichen-forming species, this would result in a few generalist photobionts associating with many specialist fungal species, as observed by Magain et al. (2017a) and $\mathrm{Lu}$ et al. (2018). This asymmetric specialization could be key to the maintenance of the lichen symbiosis, where the photobiont is transmitted mostly horizontally (i.e., the symbiosis needs to be re-established) from one generation to the next. Such asymmetric specialization is characteristic of nested interaction patterns in ecological networks (Vázquez and Aizen 2004; Joppa et al. 2010). Finding strong nestedness in lichen networks would be in line with previous studies showing that nestedness is generally prevalent in natural mutualistic networks (e.g., Bascompte et al. 2003; Fontaine et al. 2011). However, the ability for some lichens to co-disperse their mycobiont and photobiont together in specialized structures (such as soredia or isidia; i.e., vertical transmission of photobionts), or through thallus fragmentation, suggests that there may be some highly intimate interactions among subsets of mycobionts and photobionts (Otálora et al. 2010; Dal Grande et al. 2012). This should translate, at the network level, in high modularity and rather symmetrical specialization. Thus, network-based analyses have the potential to discriminate between competing hypotheses explaining the establishment and maintenance of lichenic interactions.

Studies on specificity of symbiotic associations in cyanolichens from various genera: Leptogium, Collema and Degelia (Otálora et al. 2010, 2013) indicated a link between high reciprocal specificity and vertical transmission of the photobiont, and restricted ecological niches. It was also suggested that the substrate determines the sets of cyanobionts available for sharing among mycobionts of terrestrial and epiphytic lichen guilds (Rikkinen et al. 2002) and that associations between lichen-forming fungi and their photobionts can be best explained by the interplay of vertical and horizontal transmissions of photobionts (Rikkinen 2003). However, the study by Magain et al. (2017a) supports the hypothesis that mycobiont specificity towards a specific pool of Nostoc phylogroups is inherited through time at a macroevolutionary scale with occasional switches from one cyanobiont pool to another.

Network structure may not only reflect community assembly rules, but could also suggest potential evolutionary consequences of given interaction patterns. For example, asymmetric specialization may lead to an imbalance in the reciprocal adaptation of the partners to each other. While a specialist experience strong selection pressures to adapt to its only partner, if the latter is also interacting with many other species (i.e., is a generalist), then it may not reciprocally adapt to the specialist (Vázquez et al. 2007; Guimarães et al. 2007). Guimarães et al. (2011) have shown, using a theoretical model of evolution, that generalists should have more impact on trait evolution in networks, and favor trait convergence among species at a given trophic level, to adapt to their core of generalist partners. Moreover, the presence of well-defined modules (i.e., groups of species that preferentially interact) in a network could suggest that most coevolutionary processes will take place within modules, in such a way that species belonging to the same modules will progressively co-adapt to each other. The presence of welldefined modules may thus suggest a tight coevolutionary history between sets of mycobionts and photobionts (e.g., Olesen et al. 2007; Danieli-Silva et al. 2012).

Here, we characterize the network of interactions involving lichenized fungi belonging to the section Polydactylon of the genus Peltigera (Peltigerales, Lecanoromycetes) at two spatial scales (global and local). These fungi form macrolichens with cyanobacterial partners of the genus Nostoc (Magain et al. 2017a). Section Polydactylon was shown to include ca. 40 species with different profiles of specificity towards their Nostoc partner, from strict specialists to generalists (Magain et al. 2017a, b). Previous studies demonstrated 
that Peltigera have high specificity toward their cyanobacterial partners, both locally and globally, but the degree of specificity is variable and likely influenced by factors such as the identity and phylogenetic relationships of the species, as well as geographical and ecological factors (O'Brien et al. 2013; Magain et al. 2017a; Lu et al. 2018), whereas the specificity of Nostoc appears lower but still ranging from strict specialists to generalists (O'Brien et al. 2005; Magain et al. 2017a). Our study was conducted primarily at a global spatial scale, allowing a better understanding of the ecological drivers as well as potential evolutionary consequences of these interactions at a fine phylogenetic scale, i.e., involving closely related species of the genus Peltigera that are sharing a most recent common ancestor, as part of the monophyletic section Polydactylon. To evaluate the effect of spatial scales on the driving mechanisms for network structure, we also characterized network structure at local spatial scales in British Columbia (Canada) for the entire communities of Peltigera species growing side by side, using datasets from O'Brien et al. (2009, 2013).

\section{Materials and methods}

\section{Data acquisition}

Our global dataset consists of 250 lichen specimens representing section Polydactylon of the genus Peltigera [200 from Magain et al. (2017a), 18 from Magain et al. (2017b), and 32 newly sequenced individuals (dataset 1 in Supplementary Table S1)]. These specimens were loaned from herbaria or private collections, or collected throughout the world by members of the Lutzoni lab and collaborators (Supplementary Figure S1) from a broad diversity of habitats (Magain et al. 2017a). For each thallus, both the mycobiont (fungal partner, Peltigera) and photobiont (photosynthetic partner, the nitrogen-fixing cyanobacterium Nostoc, also referred to as the cyanobiont) were identified using a molecular approach (Magain et al. 2017a, b). Briefly, for the mycobiont, the nuclear ribosomal RNA [Internal Transcribed Spacer (ITS) region and the $5^{\prime}$ end of the large subunit (nrLSU)], three protein-coding genes [partial RNA polymerase II largest subunit (RPBI), $\beta$-tubulin, and the elongation factor 2 region 1 (EFT2.1)] and three Collinear Orthologous Regions (COR), each containing one intergenic spacer, were amplified and sequenced (Magain et al. 2017a, b). We used species delimitations from Magain et al. (2017b), which were based on a consensus of five different methods [BPP, Yang and Rannala (2010); spedeSTEM, Ence and Carstens (2011); Structurama, Huelsenbeck et al. (2011); bGMYC, Reid and Carstens (2012); and bPTP, Zhang et al. (2013)]. For the cyanobiont, the $r b c \mathrm{LX}$ locus, coding for the RuBisCO large subunit $(r b c \mathrm{~L})$, and a chaperone gene $(r b c \mathrm{X})$ were amplified and sequenced to identify Nostoc haplotypes and delimit well-supported monophyletic phylogroups as proxies for species. Detailed information about the molecular data acquisition and phylogenetic methods can be found in Magain et al. (2017a, b).

For the 32 new specimens added for this study, we sequenced 28 ITS of Peltigera and $32 \mathrm{rbcLX}$ of their Nostoc partner (Supplementary Table S1) using the same methods described in Magain et al. (2017a). These sequences were included in the alignments of Magain et al. (2017b) using MacClade v. 4.08 (Maddison and Maddison 2005). The identification of the fungal and cyanobacterial partners was first attempted by sequence similarity (BLASTn; Altschul et al. 1990). If sequences were not identical to reference sequences, their identity was confirmed by performing a phylogenetic analysis with RAxML (Stamatakis 2006; Stamatakis et al. 2008) and bootstrapping, using the same parameters as in Magain et al. (2017b).

Based on this sampling of 250 specimens (dataset 1), we built an interaction matrix, with mycobiont species as columns, photobiont phylogroups as rows, and each cell representing the number of thalli in our dataset where the corresponding mycobiont and photobiont putative species were found within the same thallus (i.e., representing the frequency for each interacting partner pair). Thus, our dataset provided a quantitative (i.e., weighted) estimate of interactions, which allowed us to conduct the network-level analyses described below.

We used two additional datasets (datasets 2 and 3, Supplementary Table S1), which include all Peltigera species (i.e., not restricted to section Polydactylon) sampled from two lichen communities in British Columbia (BC), Canada (O'Brien et al. 2009, 2013). One of the local scale datasets (dataset 2) encompasses samples from 159 Peltigera thalli, which were separated by a few centimeters to $\sim 20 \mathrm{~m}$. These thalli were collected from the Spahats Creek site, located in southern British Columbia (O'Brien et al. 2013). The second local scale dataset (dataset 3 ) includes 235 thalli collected from five different sites in southern BC (Ghost Lake, Barkersville, Cameron Ridge, Battle Creek and Spahats Creek), with a maximal distance among sites of about $150 \mathrm{~km}$ (O'Brien et al. 2005, 2009, 2013). Using these two datasets of 159 and 235 specimens, respectively, we built interaction matrices the same way as described for the global scale sampling.

\section{Network analyses}

Various network-level analyses were conducted on our global and our two local datasets of lichen interactions, to answer the following three questions: (1) Are there specific groups of mycobionts and photobionts that preferentially interact together? (2) Is there evidence for reciprocal 
specialization [or for the absence of it, as commonly found in ecological networks, e.g., Joppa et al. (2009)]? (3) How might the interaction patterns observed in our datasets impact the evolution of the mycobionts and photobionts?

Question 1 Preferential interactions were identified using modularity analyses, which have become fairly popular in community ecology to detect higher level specificity in interactions. Modularity analyses were designed to not only determine if different species interact with different partners, but to also discover if there are groups of species (called modules) that share common preferred partners (e.g., Donatti et al. 2011; Mello et al. 2011). In other words, in a modular network we can partition species into modules in such a way that there will be much more interactions within rather than outside modules. Although modularity remains a simple clustering technique similar to other commonly used methods in community ecology (e.g., $k$-means, hierarchical; Chagnon 2016), one appealing property of modularity analysis is that the algorithms developed to optimize it often use a powerful optimization technique called simulated annealing. Such optimization strategy has been developed in computational sciences to solve very complex problems (sometimes referred to as NP-hard problems) within a reasonable time frame (Nourani and Andresen 1999). Although computationally intensive, this technique is particularly efficient at uncovering global maxima in optimization problems (here, the very most modular state of an interaction network). We investigated the level of modularity in our dataset following Dormann and Strauss (2014), using the bipartite R package (Dormann et al. 2009) and compared it to 1000 random scenarios to determine whether our lichen network was more modular than expected by chance alone. Those random scenarios (i.e., random interaction matrices) were generated under a conservative null model (vaznull implemented in bipartite) that aims at best preserving the total number of interactions in a network, as well as the total number of interactions for each species individually. In a nutshell, this null model uses an iterative procedure to progressively fill a random matrix with interactions, following the marginal totals of the matrix. Thus, at each iteration, a matrix cell that corresponds to a generalist photobiont and a generalist mycobiont has a much higher probability of receiving an interaction as opposed to a cell corresponding to specialist mycobionts and photobionts. After a high number of iterations, interactions are added or removed to the random matrix to ensure that the final total number of interactions mirrors the number of interactions in the original matrix. We preferred a null model that uses a probabilistic approach over a swap-based approach to fill the random matrices' cells, because in low connectance matrices such as ours, swap-based approach can be overly conservative or even fail to converge to a solution in a reasonable time (see Supplementary Methods for detailed information and discussion on the null model).

Because the sampling for dataset 1 was conducted at a global geographical scale, modularity could arise in this dataset simply because some mycobionts and photobionts are endemic to a restricted part of the world and, therefore, would be found interacting with each other more frequently than with the rest of the taxa in the dataset. This would not necessarily reflect a preferential and selective process of association between mycobionts and photobionts. To control for this biogeographical issue in structuring our modules, we performed a variance partitioning of the Bray-Curtis distance matrix among the different thalli to see whether the identity of a photobiont in a lichen thallus was best predicted by: (1) the geographic region where a lichen was sampled (2) the biome in which it was sampled, or (3) the identity of the mycobiont in the sampled thallus. This analysis is implemented in the adonis function of the R package vegan (Oksanen et al. 2017). We evaluated, also using adonis, how photobiont partner identity could be predicted by mycobiont identity within each region or biome.

Furthermore, we characterized network structure of datasets 2 and 3 collected at local scales (O'Brien et al. 2009, 2013). Collectively, these data provided interaction networks at much finer spatial scales (especially dataset 2, with thalli often within a few centimeters from each other and nearly overlapping), which should prevent modularity arising from environmental preferences: at finer spatial scales, the abiotic environment is expected to be much more homogeneous.

Question 2 Reciprocal specialization was characterized using nestedness analyses, commonly used in networkbased and $\beta$-diversity studies. In interaction networks, nestedness refers to a pattern opposed to reciprocal specialization; i.e., where specialists are interacting mostly with generalists, but not vice versa. To measure nestedness in our datasets, we used the weighted version of the NODF index (Almeida-Neto et al. 2008) developed by AlmeidaNeto and Ulrich (2011), hereafter referred to as $w N O D F$. To evaluate the statistical significance of $W N O D F$, we compared the observed $W N O D F$ value to 1000 random values generated using the same null model as described for our modularity analysis (see Supplementary Methods). We also complemented $w N O D F$ analysis with SDR analysis, developed by Podani and collaborators (Podani and Schmera 2011; Podani et al. 2013). This analysis, originally intended to characterize structural patterns in meta-communities (i.e., species $\times$ sites matrices, instead of species $\times$ species matrices for interaction networks), aims at explaining variation in partner selection in a network. Briefly, when comparing the symbiotic partners of two species, the SDR framework partitions variation into three additive components: component $\mathrm{S}$ is their similarity in partner choice, component $\mathrm{D}$ is the variation in the number 
of interactions, and component $\mathrm{R}$ is the variation in the identity of the partners for these two species. Since these three components sum to 1 , the SDR framework allows to visualize the trends present at the whole network level in a two-dimensional, ternary triangle. The $\mathrm{D}$ component of SDR is closely related to the concept of nestedness in ecological networks (i.e., the idea that the set of interactions by a more specialized species can always be included, or nested, within a set of interactions exhibited by more generalist species). However, it remains debated whether one method or the other is superior to characterize nestedness in a matrix (e.g., Ulrich and Almeida-Neto 2012; Podani and Schmera 2012). There is thus value in corroborating $w N O D F$ analysis with SDR analysis. Here, as for $w N O D F$ analyses, we took advantage of our quantitative data on species interactions to perform quantitative (not binary) SDR analyses, thus taking into account not only whether a mycobiont and a photobiont interacted together, but also at which frequency they did so.

Question 3 To explore how interaction patterns might give feedback on the evolution of the mycobionts and photobionts, we looked at interaction strength symmetry. Herein we use the term symmetric interaction to denote an interaction where two partners share the same proportion of time or effort with one another. For example, a case scenario where species $A$ spends all its interaction events with species $B$, while species $B$ is involved in many more interactions with other partners would be highly asymmetric. For lichens, the thallus offers a convenient definition of an "interaction event". Interaction symmetry is expected to impact the evolution of symbiotic systems (Vázquez et al. 2007) and, therefore, be potentially highly relevant to our understanding of symbiotic systems such as lichens. Here, we characterized interaction symmetry following Vázquez et al. (2007). Briefly, for a pair of species $i$ and $j$, the effect of species $i$ on species $j\left(\mathrm{~s}_{i j}\right)$ is the proportion of interactions of species $j$ that involve species $i$. This implies the logical assumption that if species $i$ interacts almost always with species $j$, then it will experience a higher selection pressure to adapt to its partner and derive a higher fitness benefit from this interaction than if it would interact frequently with many different species. Then, for this species pair, we calculated the difference between the reciprocal effects of species $i$ and $j$ on each other (i.e., $d_{i j}=\mathrm{s}_{i j}-\mathrm{s}_{j i}$ ). For a given species, its asymmetry $(A)$ value is defined as the mean of its " $d$-values" for all its partners. $A_{i}$ is close to 1 if species $i$ exerts strong effects on its partners while experiencing little reciprocal effects from them, and close to -1 in the reverse situation. Because the effect of a species $i$ on $j$ (i.e. $\mathrm{s}_{i j}$ ) should be linked to the selection pressure that $j$ experiences to become better adapted to $i$, looking at the symmetry in these effects should inform about coevolution in a network.

\section{Sampling completeness}

Our global sampling (dataset 1) identifies 250 interactions between lichenized fungi from the section Polydactylon of the genus Peltigera, and cyanobacterial partners from the genus Nostoc. Given the worldwide scale at which this survey was performed, 250 thalli may seem a small number. It is well known that sampling effort will impact patterns that are uncovered through network-based analyses. While it is difficult in itself to fully describe species composition in communities, it is even harder to detect all realized interactions among them (e.g., Nielsen and Bascompte 2007; Dorado et al. 2011; Chacoff et al. 2012; Rivera-Hutinel et al. 2012; Fort et al. 2016). Thus, before going further with network analyses, we verified that our sampling completeness was adequate to appropriately characterize network structure. We generated rarefaction curves for network connectance (i.e., the proportion of potential interactions between sets of species that are realized in the field), modularity and nestedness. We also followed methodology outlined by Chao et al. (2009) to evaluate our sampling completeness and the number of additional thalli that would have been necessary to fully sample our network of interactions (see Supplementary Methods). We also conducted these analyses for our two additional, local samplings (datasets 2 and 3) in British Columbia.

\section{Results}

\section{Sampling effort}

In our global sampling (dataset 1), we observed 91 different interaction pairs among our 42 Peltigera species and 43 photobiont phylogroups and unique haplotypes. Using the Chao2 estimator (Chao et al. 2009), we calculated that a complete sampling of our network could have uncovered 130 interactions. This means that our sample size (i.e., 250 thalli) allowed us to detect $70 \%$ of the interactions potentially realized between our taxa pool. Likewise, for our two local datasets, sampling completeness was estimated to be $81 \%$ for Spahats Creek (dataset 2) and $90 \%$ for all five $\mathrm{BC}$ sites combined (dataset 3 ). We were also able to estimate that about 1030 additional thalli would be necessary to detect all interactions in our global dataset, highlighting the difficulty to detect rare interaction pairs. Rarefaction curves (see Supplementary Methods) show that there is a link between sampling effort and network modularity and nestedness. However, these plots also suggest that additional sampling would only strengthen the results that we already found (see sections below), and thus our conclusions appear to be robust to sampling effort. 


\section{Modularity and preferential interactions}

Figure 1 shows the modules revealed by our global survey of Peltigera section Polydactylon (dataset 1). Rows and columns are ordered to pack the modules of preferentially interacting taxa along the matrix diagonal (i.e., not following phylogenetic relationships among mycobionts and photobionts, but rather to reflect preferences in interactions). The network modularity was statistically higher than in randomized matrices $(P=0.035)$. The identity of the photobiont in a thallus was best predicted by the mycobiont identity (39\%), while the effects of the region or the biome where the thallus was sampled remained marginal (region $=3 \%$, biome $=6 \%$ ). This finding was corroborated by additional analyses showing that the effect of mycobiont identity in predicting photobiont identity remained significant even within regions and biomes (except for Brazil, where the mycobiont and the photobiont identities were unrelated) (Supplementary Table S2). In our local datasets (2 and 3 ), the trend for modularity was in fact even stronger (dataset 2: $P<0.001$; dataset 3: $P<0.001$ ),

\section{MYCOBIONTS}

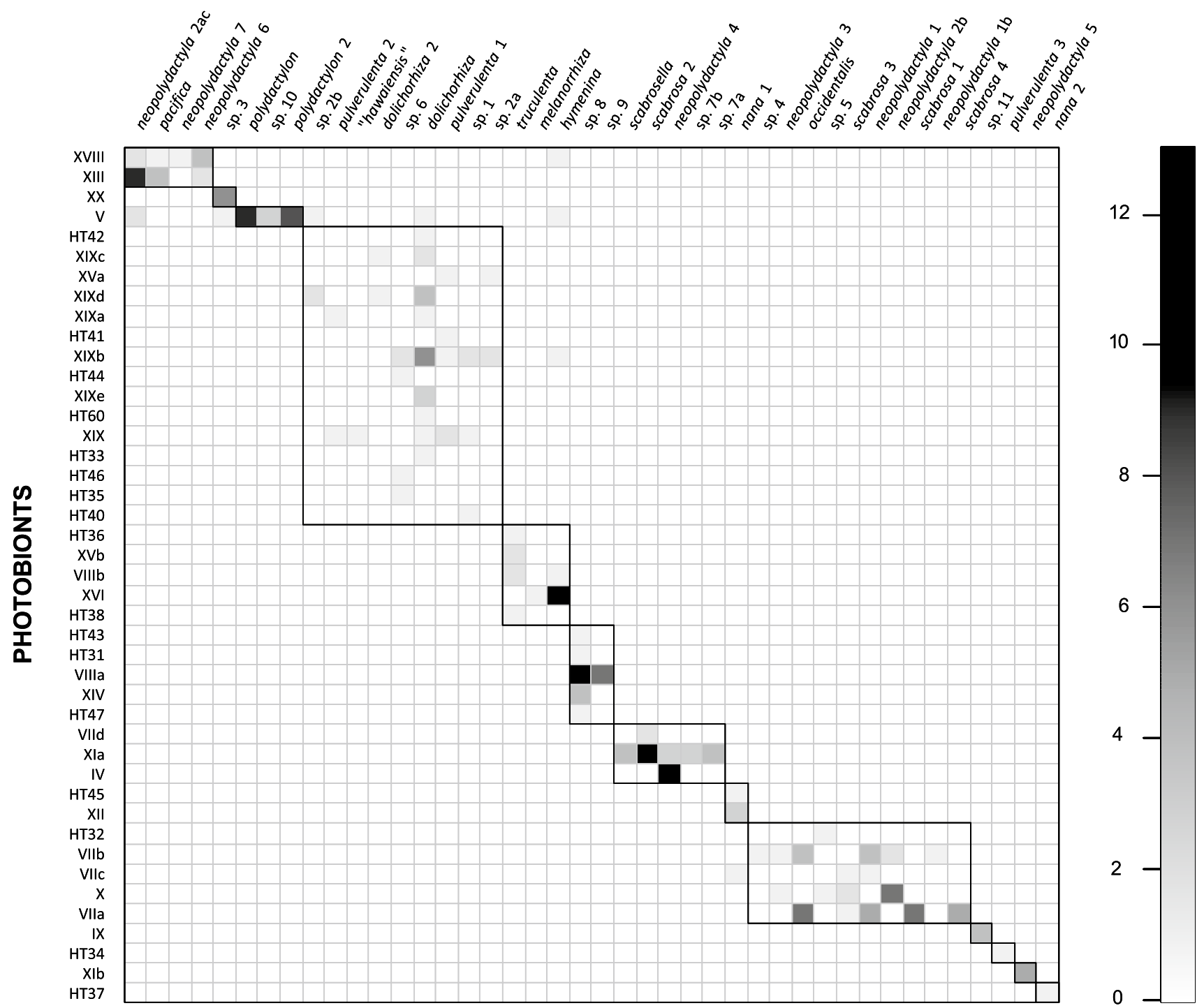

Fig. 1 Graphical depiction of the modularity analysis through the simulated annealing algorithm, showing significant modules in dataset 1 . Each column represents a mycobiont species (Peltigera, section Polydactylon) as defined by Magain et al. (2017b). Species are only designated by their epithet, i.e., omitting the genus name Peltigera. Each row represents a photobiont phylogroup (roman numerals) or haplotype (HT) sensu Magain et al. (2017a). In each cell the shade of gray is proportional to the frequency of a specific mycobiont-photobiont pair (i.e., number of thalli found with the same mycobiont and photobiont pair). The modules defined by the algorithm are delimited by dark lines and aligned along the matrix diagonal. See Supplementary Figure S2 for results from the binary modularity analysis 
indicating that modularity is not scale sensitive in this symbiotic system (Supplementary Figure S3).

\section{Nestedness and SDR analyses}

The weighted nestedness ( $w N O D F$ ) analyses for dataset 1 indicated that the interaction network was significantly less nested than expected under random scenarios (mycobionts, $P=0.003$; photobionts, $P=0.015$ ), a pattern that is sometime referred to as anti-nestedness (Poulin and Guégan 2000). This finding was corroborated by the SDR analyses, where the pairwise comparisons aligned on the left side of the ternary triangle, consistent with what is expected under antinestedness (Podani et al. 2013, Fig. 2). Similar trends were found in local datasets: the trend was significant for dataset 3 (mycobionts, $P=0.004$; photobionts, $P=0.016$ ), but not

\section{MYCOBIONTS}

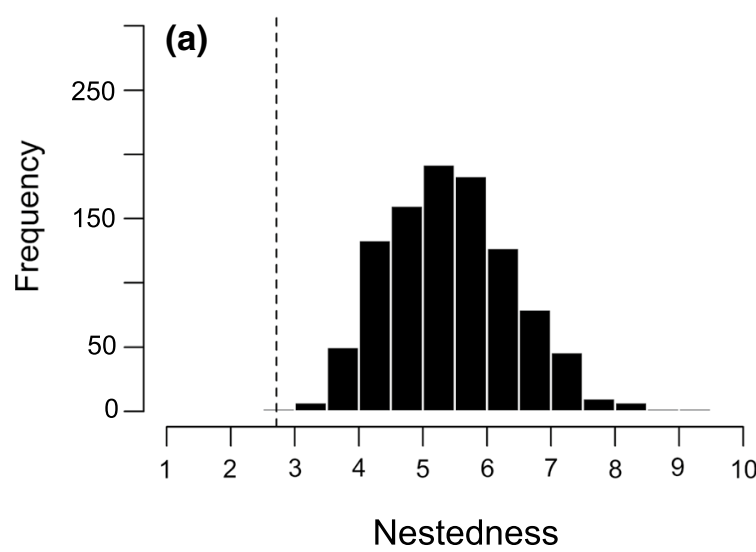

(c)

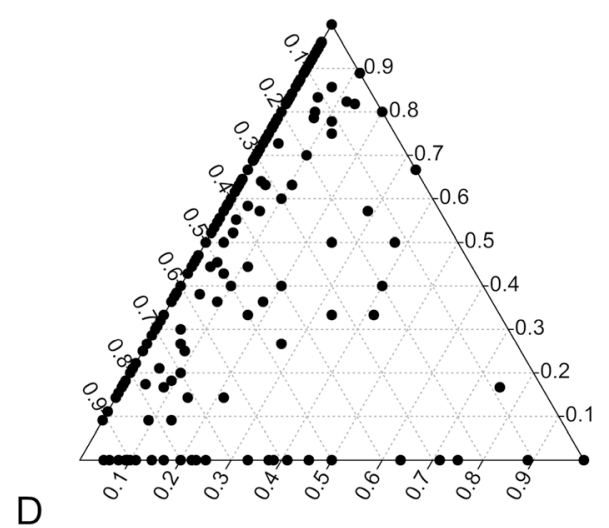

Fig. 2 Reciprocity of specialization assessed using nestedness and beta-diversity analyses (SDR; $S$ partner similarity, $D$ partner richness difference, $R$ partner replacement) in dataset 1 . Histograms of the null distributions of nestedness values (wNODF) are presented for a mycobionts and $\mathbf{b}$ photobionts. Dashed vertical lines represent the significant for dataset 2 (mycobionts, $P=0.264$; photobionts, $P=0.140$ ) (Supplementary Figure S4).

\section{Symmetry in interaction strength}

We found evidence for high prevalence of symmetric interactions at the global scale (dataset 1; Fig. 3). However, for both the mycobionts and the photobionts, some species had consistently highly negative asymmetry scores, which could represent a passive sampling effect (Vázquez et al. 2007). Rare species, which by definition have low interaction frequencies, always tend to have a smaller effect on their partners than vice versa, unless their only partners are also very rare. Therefore, species with highly negative asymmetry values might be simply rare species in the dataset. We did observe such correlation between species frequency and asymmetry scores. However, for

\section{PHOTOBIONTS}
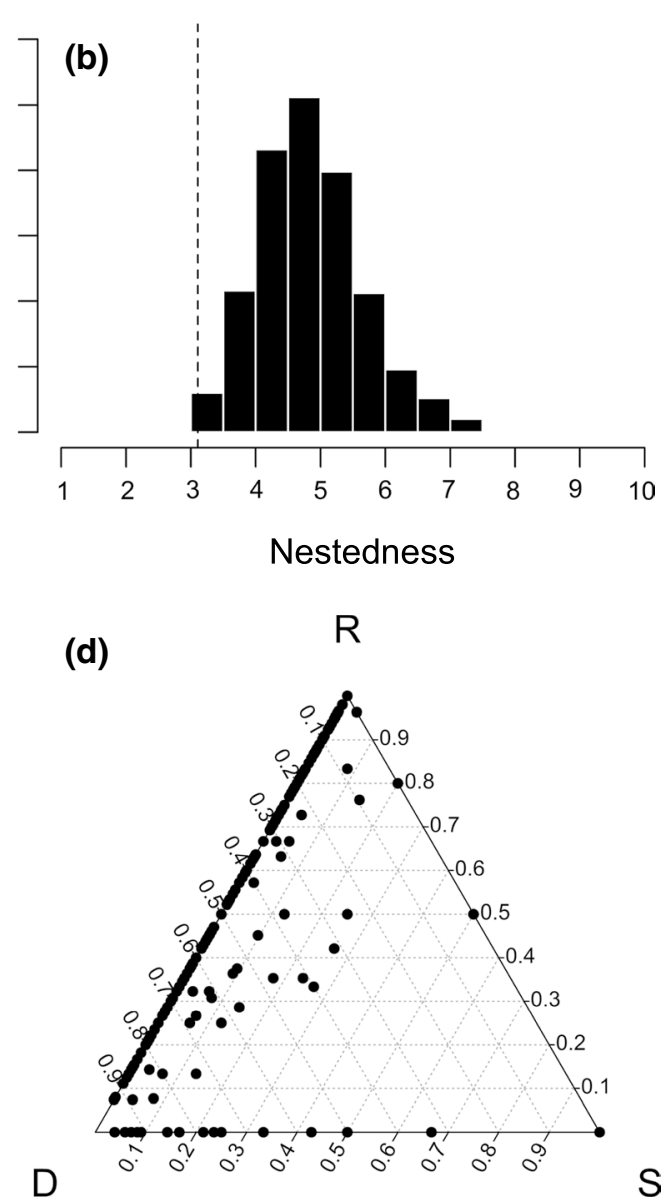

observed values in the dataset. $\mathbf{c}, \mathbf{d}$ The ternary triangles representing SDR simplex decompositions of beta-diversity following Podani et al. (2013). Each point in such triangles represents a pairwise comparison of $\mathbf{c}$ mycobiont species or $\mathbf{d}$ photobiont phylogroups 
(a)

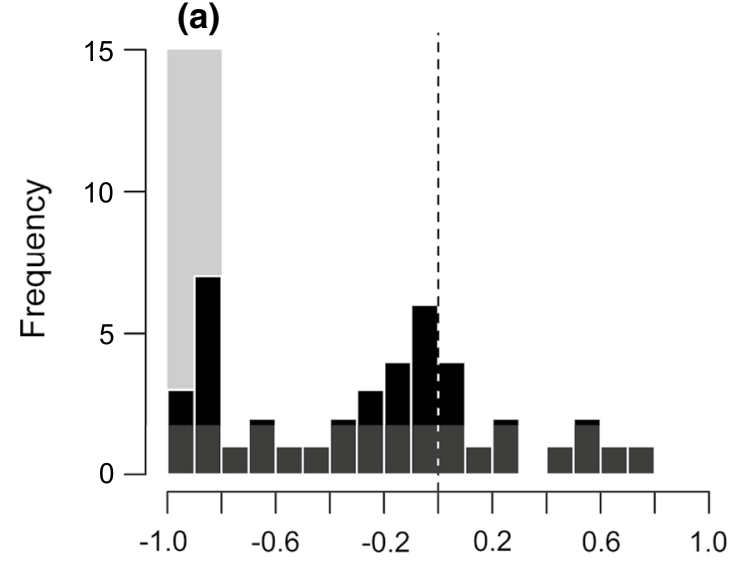

Mycobionts' asymmetries

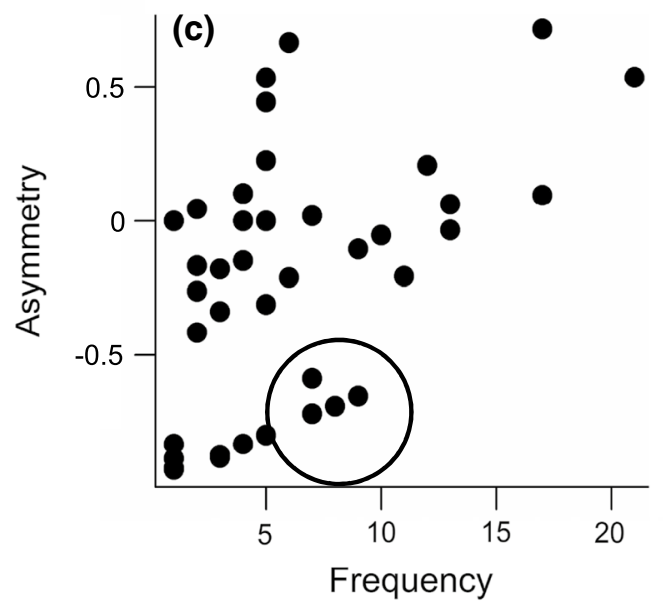

Fig. 3 Interaction symmetry among mycobionts and photobionts in dataset 1 . We show the frequency distributions of asymmetry scores for $\mathbf{a}$ mycobionts and $\mathbf{b}$ photobionts. The areas shaded in gray represent the portion of species with highly negative asymmetry scores that seem to diverge from the main, modal scores centered around 0 .

the mycobionts in the global dataset, there were also a number of species that had been sampled in several thalli, but continue to have highly negative asymmetry values. These are mycobionts truly specialized asymmetrically on generalist photobionts (e.g., phylogroup VIIa, see Fig. 1), a trend we did not detect for photobionts, which tend to be less dependent on the mycobiont (i.e., more generalists, with more phylogroups having positive asymmetry scores above 0.2 than the mycobiont; Fig. 3).

Conversely, in our local datasets 2 and 3, we found a trend for mycobionts to have mostly negative asymmetry scores (Supplementary Figure S3), which typically corresponded to interactions with a highly generalist photobiont partner having a positive asymmetry score. In dataset 3, there were also a few specialized photobionts found only (b)

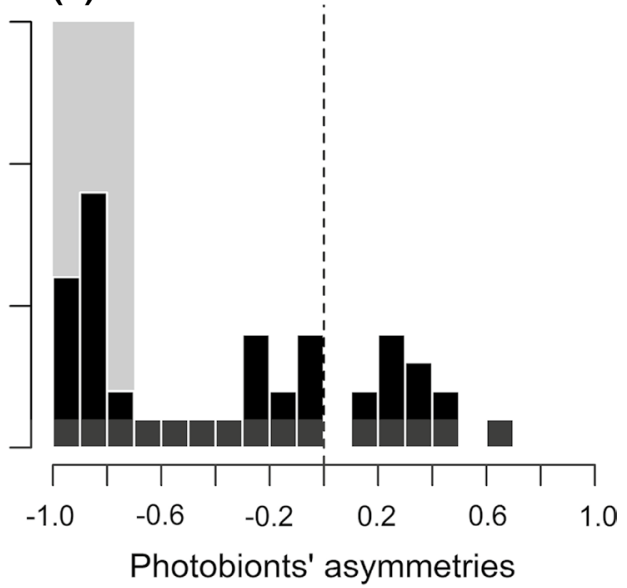

(d)

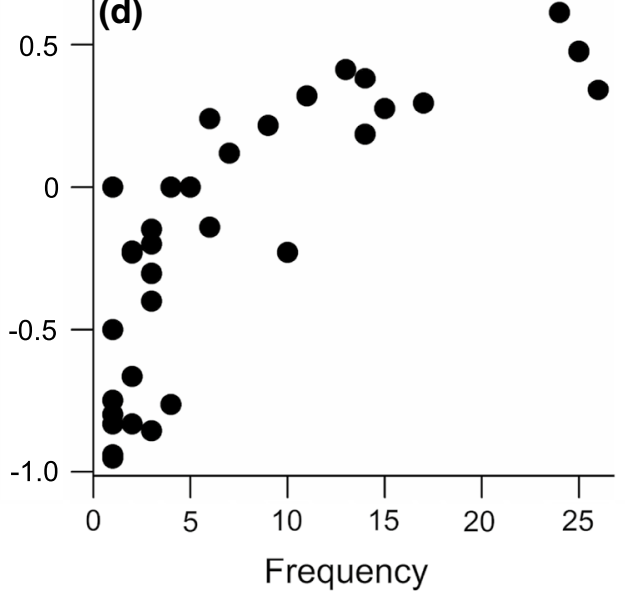

We also plot the asymmetry scores against the number of sampled thalli where a given $\mathbf{c}$ mycobiont or $\mathbf{d}$ photobiont was found. The circle in $\mathbf{c}$ represents the mycobionts for which asymmetry scores remain low even with a reasonable sampling effort (i.e., true cases of highly asymmetric specialization and dependence)

once, and these were found to have negative asymmetry scores, for reasons explained in the previous paragraph.

\section{Discussion}

In this study, we found preferential interactions among mycobionts and photobionts, as indicated by the significant modularity of the network at the global scale. However, modularity can arise in a network when species are segregated in space and/or time (e.g., Martos et al. 2012; Martín González et al. 2012; Torrecillas et al. 2014) such that all partners in the network are not available to each other. It would thus be incautious to directly link this pattern to a preferential partner selection, which implies a behavioral 
choice among multiple options. However, two additional lines of evidence allow us here to suggest that in our system, modularity truly arises from preferential, or selective, interactions: (1) the mycobiont identity in a thallus was a better predictor of the photobiont identity than the region of the globe, or the biome where the thallus was sampled; (2) modularity remained highly significant even at small spatial scales, where partner availability is not expected to prevent any interaction.

This result is in line with trends found in other lichen symbioses where mycobionts were highly selective in their photobiont choice, even at regional to global spatial scales (e.g., Yahr et al. 2004; Lindgren et al. 2014; Leavitt et al. 2015). For example, the extensive survey of the lichen-forming fungi in the family Parmeliaceae (Leavitt et al. 2015) revealed that the Oropogon fungal genus was highly selective towards a few Trebouxia algal partners, even though mycobiont species were sampled over a broad geographic range. Likewise, Lindgren et al. (2014) have found that different Bryoria mycobiont species interacted with clearly distinct subsets of the Trebouxia algal phylogeny. These studies, and others as well (e.g., Yahr et al. 2006, but see Leavitt et al. 2013) show that high selectivity in mycobiont-photobiont interactions is not unique to cyanolichens (i.e., involving a cyanobacterial photobiont; Stenroos et al. 2006, and this study).

However, our results stand in contrast with many studies showing that some mycobionts and/or photobionts are endemic to restricted regions or parts of the world, either because of historical effects or because of their response to environmental filters (Fernández-Mendoza et al. 2011; Peksa and Škaloud 2011; Nadyeina et al. 2014; Dal Grande et al. 2014), which can drive their interaction patterns. Indeed, interaction establishment between mycobionts and photobionts is a hierarchical process (Yahr et al. 2006) that intuitively relies on these sequential steps when the lichenforming fungus is reproducing sexually (e.g., ascospores): the partners must (1) co-occur and encounter each other, and (2) establish a compatible interaction. Then an additional filter can determine the fitness outcome of the interaction for the partners, and perhaps drive selectivity patterns observed in the field.

Here, we found high specificity even at the smallest spatial scale under investigation, where environmental heterogeneity was unlikely to drive mycobionts' and photobionts' spatial distribution. This is congruent, though, with another study on the epiphytic mycobiont Evernia mesomorpha showing that this fungus was not sharing its algal partner with other epiphytic mycobionts co-occurring locally (Piercey-Normore 2009). The next frontier will be to evidence what physiological/molecular traits drive these preferential associations. Such data would allow to better predict future interaction establishment and potentially coextinction cascades (e.g., Gravel et al. 2013). It has been argued that mycobionts forming fruticose lichens may select more strongly for drought-adapted photobionts (Leavitt et al. 2015), and there is empirical evidence that the substrate of lichenized fungi can predict to some extent their photobiont identity (e.g., Rikkinen et al. 2002; Elvebakk et al. 2008). However, studies have yet to uncover the biochemical traits that mediate compatibility between mycobionts and photobionts (Lindgren et al. 2014).

Our network was also found to be anti-nested, that is, to show a lower level of nestedness than expected under a random scenario. As for modularity, this trend was found to be robust to spatial scales of sampling (although the trend was not significant for dataset 2 , which was caused by the presence of one highly generalist photobiont). Given the very low connectance (5\%) of our network, low nestedness values were not surprising as it is well known that nestedness covaries positively with connectance (e.g., Almeida-Neto et al. 2008). However, since our null model controlled for connectance (such that every randomized matrix had the same connectance as the original dataset), the anti-nestedness pattern found here cannot simply be ascribed to a low network connectance.

Many theoretical studies have suggested that nestedness should stabilize mutualistic networks, potentially because it prevents coextinction cascades (e.g., Memmott et al. 2004; Burgos et al. 2007; Thébault and Fontaine 2010). Fontaine et al. (2011) have interpreted the high prevalence of nestedness in natural mutualistic communities as a validation of such theoretical result. However, here, it must be stressed that our global sampling scheme (dataset 1) does not reflect a community per se and, therefore, it would be irrelevant to interpret our results in the light of the above-mentioned studies. With such a global sampling scheme, our results on nestedness may evidence potential trade-offs in partner acquisition by lichen mycobionts and photobionts. For example, our anti-nestedness trend means that when two species share two partners, it is highly likely that species \#1 will interact more frequently with partner \#1, and species \#2 will interact more frequently with partner \#2. Anti-nestedness may thus indicate a potential trade-off that photobionts and mycobionts face when selecting partners, i.e., being a better partner for a given species implies being a worse partner for another species and, therefore, generalists here would be doomed to be "jack-of-all-trades but masters of none" (Wilson and Yoshimura 1994).

Such anti-nestedness has been reported in antagonistic networks involving marine fishes and their ectoparasites (Poulin and Guégan 2000), which could be explained by an analogous trade-off between being able to exploit many hosts versus efficiently exploiting each host (Poulin 1998). This goes against the niche-breadth hypothesis suggesting that generalist mycobionts and photobionts interacting 
with many potential partners would increase in abundance or frequency because of this particular ability to interact with many different partners (Krasnov et al. 2004; Drovetski et al. 2014). Such generalism could increase, for example, the reliability to find a compatible partner in a novel environment, which is critical for lichens lacking vertical transmission systems and reproducing sexually (Belinchón et al. 2015). Here, our results rather suggest that the range of potential partners is not the main factor limiting niche breadth and range expansion for Peltigera (section Polydactylon) fungi and Nostoc photobionts, which is in agreement with the results from Lu et al. (2018) at an intrabiome scale. This contradicts other results showing that generalist mycobionts achieve a wider geographical niche (Wirtz et al. 2003; Muggia et al. 2014). High generalism has been hypothesized to be a favorable attribute allowing the colonization of novels habitats and thus favoring range expansion (Magain et al. 2017a). Conversely, it remains unknown whether highly specialized lichenized fungi experience a cost for such specialization, where a slight decrease in their preferred photobionts can drive their rarity. This would parallel the trend observed for the terrestrial orchid Caladenia huegelii specializing on a narrow subset of mycorrhizal fungi essential for its germination that seems to explain its rarity in Western Australia (Swarts et al. 2010).

By showing anti-nestedness for a mutualistic lichen network, our results also stand in contrast with other studies frequently reporting that mutualistic systems tend to be more nested, and antagonistic systems more compartmented (i.e., modular; e.g., Thébault and Fontaine 2010; Wardhaugh et al. 2015). This is in line, though, with results demonstrating that within mutualisms, interactions of high intimacy (that is, closed and sustained interactions, such as when a symbiont spends a significant portion of its life cycle with a host) should be more modular and less nested (Guimarães et al. 2007; Fontaine et al. 2011). This prediction stems from the idea that intimate interactions require more physiological integration of the partners, and thus place more constraints on the establishment of interactions with many different partners bearing different traits (Price 1980). However, this prediction is not coherent with the high levels of nestedness found in some mycorrhizal networks (e.g., Montesinos-Navarro et al. 2012), which are obviously intimate and involve the fungi placing a significant portion of their biomass within the plants' roots, and initiating a complex biochemical and molecular dialog with the host (e.g., Plett et al. 2014; Bonfante and Genre 2015). Similar nested patterns were found for endolichenic fungi [i.e., cryptic fungal communities inhabiting lichen thalli (lichen mycobiota)], which should also be considered an intimate interaction (Chagnon et al. 2016), while intimate interactions between plant leaves and their fungal endophytes showed higher host-specificity and modularity based on a culturedependent approach (Chagnon et al. 2016).

Collectively, these findings and our current study highlight that our coarse delineation of interaction types as "mutualistic" or "antagonistic", or as having high or low "intimacy" fails at predicting the architecture of interaction networks. Instead, it seems much more probable that the network structure rather reflects more basic properties related to the system, or how it has been sampled. For example, as the spatial scale of a study increases, for a given sampling effort, it should be expected that the proportion of interactions that remain undetected among the large pool of species found within the area of the study will increase, thus decreasing connectance. This could reduce nestedness (Almeida-Neto et al. 2008). Moreover, as environmental heterogeneity increases in a given study area, the odds increase that some species pairs never encounter each other because they remain in their own respective preferred or suitable habitat (e.g., Torrecillas et al. 2014; Fernández-Mendoza et al. 2011; Nadyeina et al. 2014). Thus, network modularity should increase. This issue has been recognized when dealing with species co-occurrence patterns, and trying to infer potential positive or negative interactions from these patterns (e.g. Ovaskainen et al. 2010; Bar-Massada and Belmaker 2017). Network structure may also not necessarily be caused by sampling artifacts, but rather reflect more subtle characteristics of the interaction investigated. For example, Chagnon et al. (2016) compared the network structure for two types of "intimate" interactions (endolichenic and leaf endophytic fungi) that were sampled following the same culture-based protocol, in the same sites, and found them to show very contrasted structures. As a result, network structure does tell us some information about the properties of an interaction: it may simply be subtler than the interaction being mutualistic or antagonistic, or intimate or not.

Our study provides a framework for exploring the potential evolutionary consequences of interaction patterns in the lichen network. Coevolution in symbiotic systems has long been a matter of debate (Thompson 2009). The recognition that coevolution takes place in species-rich communities (e.g., microbiota), with many potential indirect effects among species, has led some researchers to argue that coevolution among species is diffuse (Inouye and Stincombe 2001; Strauss and Irwin 2004) and, consequently, difficult to predict in any reductionist way (Levin et al. 1990). However, recent advances in ecological network theory have suggested that looking at symmetry of interactions could be a useful tool to explore the coevolutionary process (Vázquez et al. 2007).

This might be especially true in our study system, section Polydactylon, where the number of generalists and interacting taxa is low, and thus, so are the potential indirect coevolutionary effects. Contrary to many mutualistic networks 
investigated to date (e.g., Bascompte et al. 2006; Vázquez et al. 2007), we found that interaction strengths were fairly symmetrical in this lichen group at the global scale. However, at the local scale (in BC), a different pattern emerged, whereby a few generalist photobionts disproportionately influence their specialized mycobionts. The same pattern was observed for Peltigera in the province of Québec at an intraboreal scale (Lu et al. 2018). Some examples of asymmetrical specialization were also evidenced at the global scale (e.g., mycobionts specialized on Nostoc phylogroup VIIa). This is in line with our current overall understanding of the lichen symbiosis involving an asymmetry in dependence, whereby mycobionts are more dependent on their photoautotrophic partners than vice versa (Lutzoni and Miadlikowska 2009). This is reflected by the inability (so far) to grow the mycobiont (Peltigera), and the relative ease to isolate the cyanobiont in pure culture. Moreover, Peltigera, as most lichen-forming fungi, has never been observed in a free-living state, whereas there is evidence suggesting that Nostoc phylogroups partnering with Peltigera can be freeliving in nature (O'Brien et al. 2005; Zúñiga et al. 2017).

The issue of dependence on the partners also has important ramifications to the evolutionary stability of mutualisms: heavy reliance on a partner could promote the emergence of a cheating strategy in this partner (e.g., Steidinger and Bever 2014). Some have suggested that a host keeping symbionts captive within a given compartment (e.g., rhizobia in nodules) could be prone to cheat on these symbionts (Johnstone and Bshary 2002, but see Porter and Simms 2014). Here, the lichen mutualism represents a conflicting example whereby the mycobionts keep the photobionts within the thallus, but are also more dependent on them than vice versa. From the asymmetry analyses presented here, we could expect photobionts to be in the driver seat, even if they are sometime perceived as "captive" within fungal biomass. Indeed, at the local scales, specialized mycobionts appear to experience a stronger pressure to adapt to their generalist photobiont than vice versa. This could in fact promote cheating on the mycobionts by the photobionts. On the other hand, it is well known that mutualistic interactions can be stabilized against cheating by mechanisms that allow to favor beneficial interactions and/or terminate detrimental interactions (e.g., Ferriere et al. 2002; Kiers et al. 2003). For example, the ability of plants to preferentially reward most beneficial mycorrhizal fungi has been suggested to stabilize the mutualism (Bever et al. 2009; Kiers et al. 2011). The existence of similar mechanisms for mycobionts to favor interactions with cooperating photobionts may stabilize the lichen mutualism in a similar way. Horizontal transmission of the photobiont, which enhances the possibility for photobiont switches, may represent such mechanism. Interestingly, the pool of free-living photobionts, even sometimes observed at the surface of existing thalli (Muggia et al. 2013), may provide a propagule pool for mycobionts to screen for cooperating partners over time.

Finally, the network study presented here represents an interesting addition to other studies on cyanolichens trying to identify higher level structure in mycobiont-photobiont partnerships. Indeed, Rikkinen et al. (2002) have shown that lichen guilds (i.e., the Peltigera guild and the Nephroma guild) hosted distinct Nostoc photobionts, which is analogous to a modular network structure. Here, our study uncovers guilds within guilds, in that the Peltigera guild of Rikkinen et al. (2002) is probably itself subdivided into smaller modules. This has interesting implications for potential interactions among mycobionts following the perspective of Rikkinen et al. (2002) that mycobionts being part of the same guild may in a way facilitate each other in their joined effort to maintain a pool of shared cyanobionts. This should be explored in future studies using co-occurrence network analyses at local to regional scales. Recently developed statistical approaches could identify pairs of mycobionts that co-occurred more frequently than what is predicted based on their habitat preferences or geographical ranges (Ovaskainen et al. 2017). The sharing of photobionts within guilds could be one cause explaining such co-occurrences. However, the study of Magain et al. (2017a) revealed that these modules are phylogenetically structured to various degrees, i.e., Peltigera species sharing the same set of Nostoc phylogroups are closely related (part of distinct clades). This is suggesting that specificity to a specific shared pool of Nostoc phylogroups is inherited and contribute to the pattern of associations found in lichen communities. This is observed also across the class Lecanoromycetes where specific monophyletic groups of lichens are specialized on specific groups of photobionts (Miadlikowska et al. 2006, 2014).

\section{Conclusion and future directions}

Our datasets revealed preferential interactions among Peltigera mycobionts and Nostoc photobionts at both global and local geographical scales, as reflected by our modularity analyses. Those preferential interactions are also visible in an anti-nestedness pattern. Apparently, there may be a trade-off, especially for the mycobiont, whereby interacting more with a given partner implies interacting less with others and interacting with many taxa implies interacting less with any given partner. It should be noted that specialized interaction patterns may seem surprising at such a fine phylogenetic scale (i.e., a single section within a single genus, Peltigera). More specialized interactions may be the norm for interactions being sampled at broader phylogenetic scales [e.g., leaf-fungal endophytic networks where a broad array of Pezizomycotina fungi are interacting with hosts ranging from bryophytes to ligneous angiosperms and 
gymnosperms, see Chagnon et al. (2016)], because species that have diverged for extensive periods of time are expected to bear contrasted traits, which should make them select different interacting partners (Rezende et al. 2007; Gómez et al. 2010). Here such high specialization among closely related Peltigera species may be the intriguing exception rather than the rule in fungal-photobiont systems, but a common trend in cyanolichens and perhaps lichens in general. This will require further research at various phylogenetic scales in lichens (perhaps starting by integrating various sections of this species rich, Peltigera genus).

Future research will be necessary to better understand the relative importance of ecological versus evolutionary mechanisms in driving the assembly of this lichen network. Do preferential interactions arise because species select partners that maximize their fitness (evolutionary and ecological mechanism), or because of past coevolution in various geographic areas (Thompson 2009)? Also, what allows a photobiont to become highly generalist? Is it due to specific traits, or simply the result of a high local abundance? If so, then different photobionts may become generalists in different regions, which could create a geographic mosaic of Peltigera adaptation to their most common local photobiont. Sampling along gradients using transects at intermediate geographical scales such as within biomes (e.g., Lu et al. 2018) and across inter-biome ecotones might unveil the trends and patterns needed to better understand the eco-evolutionary mechanisms shaping photoautotrophs-heterotrophs symbiotic interactions.

Acknowledgements We are very thankful to many people that assisted us during various Peltigera collecting trips, as well as collaborators and curators of herbaria for providing material for this study.

Author contribution statement PLC, NM, JM and FL planned and designed the research, NM, JM and FL conducted samplings and molecular analyses, PLC conducted numerical analyses, and PLC, NM, $\mathrm{JM}$ and FL wrote the manuscript.

Funding This work was supported by the National Science Foundation (DEB-1025930 and DEB-1556995 to J.M. and F.L.), the Belgium American Educational Foundation (post-doctoral fellowship to N.M.) and the Killam Trust and Fonds de la Recherche du Québec, Nature et Technologies (post-doctoral fellowships to P.L.C.).

\section{Compliance with ethical standards}

Conflict of interest The authors declare that they have no conflict of interest.

\section{References}

Almeida-Neto M, Ulrich W (2011) A straightforward computational approach for measuring nestedness using quantitative matrices.
Environ Model Softw 26:173-178. https://doi.org/10.1016/j. envsoft.2010.08.003

Almeida-Neto M, Guimarães P, Guimarães JPR, Loyola RD, Ulrich W (2008) A consistent metric for nestedness analysis in ecological systems: reconciling concept and measurement. Oikos 117:12271239. https://doi.org/10.1111/j.0030-1299.2008.16644.x

Altschul SF, Gish W, Miller W, Lipman DJ (1990) Basic local alignment search tool. J Mol Biol 215:403-410. https://doi. org/10.1016/S0022-2836(05)80360-2

Bar-Massada A, Belmaker J (2017) Non-stationarity in the co-occurrence patterns of species across environmental gradients. J Ecol 105:391-399. https://doi.org/10.1111/1365-2745.12713

Bascompte J, Jordano P, Melián CJ, Olesen JM (2003) The nested assembly of plant-animal mutualistic networks. Proc Natl Acad Sci USA 100:9383-9387. https://doi.org/10.1073/pnas.16335 76100

Bascompte J, Jordano P, Olesen JM (2006) Asymetric Coevolutionary networks facilitate biodiversity maintenance. Science 312:431433. https://doi.org/10.1126/science.1123412

Belinchón R, Yahr R, Ellis CJ (2015) Interactions among species with contrasting dispersal modes explain distributions for epiphytic lichens. Ecography 38:762-768

Bever JD, Richardson SC, Lawrence BM, Holmes J, Watson M (2009) Preferential allocation to beneficial symbiont with spatial structure maintains mycorrhizal mutualism. Ecol Lett 12:13-21. https ://doi.org/10.1111/j.1461-0248.2008.01254.x

Bonfante P, Genre A (2015) Arbuscular mycorrhizal dialogues: do you speak "plantish" or "fungish"? Trends Plant Sci 20:150-154

Burgos E, Ceva H, Perazzo RPJ, Delbue AM (2007) Why nestedness in mutualistic networks? J Theor Biol 249:307-313. https://doi. org/10.1016/j.jtbi.2007.07.030

Burns KC (2013) What causes size coupling in fruit-frugivore interaction webs? Ecology 94:295-300. https://doi. org/10.1890/12-1161.1

Chacoff NP, Vázquez DP, Lomáscolo SB, Stevani EL, Dorado J, Padron B (2012) Evaluating sampling completeness in a desert plantpollinator network. J Anim Ecol 81:190-200. https://doi.org/10 $.1111 / \mathrm{j} .1365-2656.2011 .01883 . x$

Chagnon PL (2016) Seeing networks for what they are in mycorrhizal ecology. Fungal Ecol 24:148-154. https://doi.org/10.1016/j.funec o.2016.05.004

Chagnon PL, Bradley RL, Klironomos JN (2015) Trait-based partner selection drives mycorrhizal network assembly. Oikos 124:16091616. https://doi.org/10.1111/oik.01987

Chagnon PL, U'Ren JM, Miadlikowska J, Lutzoni F, Arnold AE (2016) Interaction type influences ecological network structure more than local abiotic conditions: evidence from endophytic and endolichenic fungi at a continental scale. Oecologia 180:181191. https://doi.org/10.1007/s00442-015-3457-5

Chao A, Colwell RK, Lin CW, Gotelli NJ (2009) Sufficient sampling for asymptotic minimum species richness estimators. Ecology 90:1125-1133. https://doi.org/10.1890/07-2147.1

Dal Grande F, Widmer I, Wagner HH, Scheidegger C (2012) Vertical and horizontal photobiont transmission within populations of a lichen symbiosis. Mol Ecol 21:3159-3172. https://doi. org/10.1111/j.1365-294X.2012.05482.x

Dal Grande F, Beck A, Cornejo C, Singh G, Cheenacharoen S, Nelsen MP, Scheidegger C (2014) Molecular phylogeny and symbiotic selectivity of the green algal genus Dictyochloropsis s.l. (Trebouxiophyceae): a polyphyletic and widespread group forming photobiont-mediated guilds in the lichen family Lobariaceae. New Phytol 202:455-470. https://doi.org/10.1111/nph.12678

Danieli-Silva A, de Souza JMT, Donatti AJ, Campos RP, Vicente-Silva J, Freitas L, Varassin IG (2012) Do pollination syndromes cause modularity and predict interactions in a pollination network in 
tropical high-altitude grasslands? Oikos 121:35-43. https://doi. org/10.1111/j.1600-0706.2011.19089.x

Donatti CI, Guimarães PR, Galetti M, Pizo MA, Marquitti FMD, Dirzo $R$ (2011) Analysis of a hyper-diverse seed dispersal network: modularity and underlying mechanisms. Ecol Lett 14:773-781. https://doi.org/10.1111/j.1461-0248.2011.01639.x

Dorado J, Vá Zquez DP, Stevani EL, Chacoff NP (2011) Rareness and specialization in plant-pollinator networks. Ecology 92:19-25. https://doi.org/10.1890/10-0794.1

Dormann CF, Strauss R (2014) A method for detecting modules in quantitative bipartite networks. Methods Ecol Evol 5:90-98. https://doi.org/10.1111/2041-210X.12139

Dormann CF, Fründ J, Blüthgen N, Gruber G (2009) Indices, graphs and null models: analysing bipartite ecological networks. Open Ecol J 2:7-24. https://doi.org/10.2174/1874213000902010007

Drovetski SV, Aghayan SA, Mata VA, Lopes RJ, Mode NA, Harvey JA, Voelker G (2014) Does the niche breadth or trade-off hypothesis explain the abundance-occupancy relationship in avian Haemosporidia? Mol Ecol 23:3322-3329. https://doi.org/10.1111/ mec. 12744

Dupont YL, Hansen DM, Olesen JM (2003) Structure of a plantflower-visitor network in the high-altitude sub-alpine desert of Tenerife, Canary Islands. Ecography (Cop) 26:301-310. https:// doi.org/10.1034/j.1600-0587.2003.03443.x

Dupont YL, Padrón B, Olesen JM, Petanidou T (2009) Spatio-temporal variation in the structure of pollination networks. Oikos 118:1261-1269. https://doi.org/10.1111/j.1600-0706.2009.17594 X

Elvebakk A, Papaefthimiou D, Robertsen EH, Liaimer A (2008) Phylogenetic patterns among Nostoc cyanobionts within bi- and tripartite lichens of the genus Pannaria. J Phycol 44:1049-1059. https://doi.org/10.1111/j.1529-8817.2008.00556.x

Ence DD, Carstens BC (2011) SpedeSTEM: a rapid and accurate method for species delimitation. Mol Ecol Resour 11:473-480. https://doi.org/10.1111/j.1755-0998.2010.02947.x

Fernández-Mendoza F, Domaschke S, García MA, Jordan P, Martin MP, Printzen C (2011) Population structure of mycobionts and photobionts of the widespread lichen Cetraria aculeata. Mol Ecol 20:1208-1232. https://doi.org/10.1111/j.1365294X.2010.04993.x

Ferriere R, Bronstein JL, Rinaldi S, Law R, Gauduchon M (2002) Cheating and the evolutionary stability of mutualisms. Proc Biol Sci 269:773-780. https://doi.org/10.1098/rspb.2001.1900

Feuerer T, Hawksworth DL (2007) Biodiversity of lichens, including a world-wide analysis of checklist data based on Takhtajan's floristic regions. Biodivers Conserv 16:85-98. https://doi.org/10.1007/ s10531-006-9142-6

Fontaine C, Guimarães PR, Kéfi S, Loeuille N, Memmott J, van der Putten WH, van Veen FJF, Thébault E (2011) The ecological and evolutionary implications of merging different types of networks. Ecol Lett 14:1170-1181. https://doi.org/10.111 1/j.1461-0248.2011.01688.x

Fort H, Vázquez DP, Lan BL (2016) Abundance and generalisation in mutualistic networks: solving the chicken-and-egg dilemma. Ecol Lett 19:4-11. https://doi.org/10.1111/ele.12535

Gómez JM, Verdú M, Perfectti F (2010) Ecological interactions are evolutionarily conserved across the entire tree of life. Nature 465:918-921. https://doi.org/10.1038/nature09113

Gravel D, Poisot T, Albouy C, Velez L, Mouillot D (2013) Inferring food web structure from predator-prey body size relationships. Methods Ecol Evol 4:1083-1090. https://doi. org/10.1111/2041-210X.12103

Guimarães PR, Rico-Gray V, dos Reis SF, Thompson JN (2006) Asymmetries in specialization in ant-plant mutualistic networks. Proc Biol Sci 273:2041-2047. https://doi.org/10.1098/rspb.2006.3548
Guimarães PR, Rico-Gray V, Oliveira PS, Izzo TJ, dos Reis SF, Thompson JN (2007) Interaction intimacy affects structure and coevolutionary dynamics in mutualistic networks. Curr Biol 17:1797-1803. https://doi.org/10.1016/j.cub.2007.09.059

Guimarães PR, Jordano P, Thompson JN (2011) Evolution and coevolution in mutualistic networks. Ecol Lett 14:877-885. https://doi. org/10.1111/j.1461-0248.2011.01649.x

Herrera CM (1982) Breeding systems and dispersal-related maternal reproductive effort of southern spanish bird-dispersed plants. Evolution 36:1299-1314. https://doi.org/10.2307/2408162

Huelsenbeck JP, Andolfatto P, Huelsenbeck ET (2011) Structurama: Bayesian inference of population structure. Evol Bioinforma 2011:55-59. https://doi.org/10.4137/EBO.S6761

Inouye B, Stinchcombe JR (2001) Relationships between ecological interaction modifications and diffuse coevolution: similarities, differences, and causal links. Oikos 95:353-360. https://doi.org /10.1034/j.1600-0706.2001.950218.x

Johnstone RA, Bshary R (2002) From parasitism to mutualism: partner control in asymmetric interactions. Ecol Lett 5:634-639. https:// doi.org/10.1046/j.1461-0248.2002.00358.x

Joppa LN, Bascompte J, Montoya JM, Solé RV, Sanderson J, Pimm SL (2009) Reciprocal specialization in ecological networks. Ecol Lett 12:961-969. https://doi.org/10.111 1/j.1461-0248.2009.01341.x

Joppa LN, Montoya JM, Solé R, Pimm SL (2010) On nestedness in ecological networks. Evol Ecol Res 12:35-46

Jordano P (1987) Patterns of mutualistic interactions in pollination and seed dispersal: connectance, dependence asymmetries, and coevolution. Am Nat 129:657-677. https://doi.org/10.1086/284665

Kembel SW, O'Connor TK, Arnold HK, Hubbell SP, Wright SJ, Green JL (2014) Relationships between phyllosphere bacterial communities and plant functional traits in a neotropical forest. Proc Natl Acad Sci USA 111:13715-13720. https://doi.org/10.1073/ pnas.1216057111

Kiers ET, Rousseau RA, West SA, Denison RF (2003) Host sanctions and the legume-rhizobium mutualism. Nature 425:78-81. https ://doi.org/10.1038/nature01931

Kiers ET, Duhamel M, Beesetty Y, Mensah JA, Franken O, Verbruggen E, Fellbaum CR, Kowalchuk GA, Hart MM, Bago A, Palmer TM, West SA, Vandenkoornhuyse P, Jansa J, Bücking H (2011) Reciprocal rewards stabilize cooperation in the mycorrhizal symbiosis. Science 333:880-882. https://doi.org/10.1126/scien ce. 1208473

Kirk P, Ainsworth G, Bisby G (2008) Dictionary of the fungi. CABI Publishing, Wallingford

Krasnov BR, Poulin R, Shenbrot GI, Mouillot D, Khokhlova IS (2004) Ectoparasitic "Jacks-of-All-Trades": relationship between abundance and host specificity in fleas (Siphonaptera) parasitic on small mammals. Am Nat 164:506-516. https://doi. org/10.1086/423716

Leavitt SD, Nelsen MP, Lumbsch HT, Johnson LA, St-Clair LL (2013) Symbiont flexibility in subalpine rock shield lichen communities in the Southwestern USA. Bryologist 116:149-161. https://doi. org/10.1639/0007-2745-116.2.149

Leavitt SD, Kraichak E, Nelsen MP, Altermann S, Divakar PK, Alors D, Esslinger TL, Crespo A, Lumbsch T (2015) Fungal specificity and selectivity for algae play a major role in determining lichen partnerships across diverse ecogeographic regions in the lichen-forming family Parmeliaceae (Ascomycota). Mol Ecol 24:3779-3797. https://doi.org/10.1111/mec.13271

Levin SA, Segel LA, Adler FR (1990) Diffuse coevolution in plantherbivore communities. Theor Popul Biol 37:171-191. https:// doi.org/10.1016/0040-5809(90)90034-S

Lindgren H, Velmala S, Högnabba F, Goward T, Holien H, Myllys L (2014) High fungal selectivity for algal symbionts in the genus 
Bryoria. Lichenol 46:681-695. https://doi.org/10.1017/S0024 282914000279

Lu J, Magain N, Miadlikowska J, Coyle J, Truong C, Lutzoni F (2018) Patterns of symbiotic associations between Peltigera and Nostoc at an intrabiome scale. Am J Bot (in press)

Lutzoni F, Miadlikowska J (2009) Lichens. Curr Biol. https://doi. org/10.1016/j.cub.2009.04.034

Lutzoni F, Pagel M, Reeb V (2001) Major fungal lineages are derived from lichen symbiotic ancestors. Nature 411:937-940. https:// doi.org/10.1038/35082053

Maddison D, Maddison W. (2005) MacClade v. 4.08. Sunderland: Sinauer Associates

Magain N, Miadlikowska J, Goffinet B, Sérusiaux E, Lutzoni F (2017a) Macroevolution of specificity in cyanolichens of the genus Peltigera section Polydactylon (Lecanoromycetes, Ascomycota). Syst Biol 66:74-99. https://doi.org/10.1093/sysbio/syw065

Magain N, Miadlikowska J, Mueller O, Gajdeczka M, Salamov AA, Dubchak I, Grigoriev I, Goffinet B, Sérusiaux E, Lutzoni F (2017b) Conserved genomic collinearity as a source of broadly applicable, fast evolving, markers to resolve species complexes: a case study using the lichen-forming genus Peltigera section Polydactylon. Mol Phyl Evol 117:10-29

Maglianesi MA, Blüthgen N, Böhning-Gaese K, Schleuning M (2015) Functional structure and specialization in three tropical planthummingbird interaction networks across an elevational gradient in Costa Rica. Ecography (Cop) 38:1119-1128. https://doi. org/10.1111/ecog.01538

Martín González AM, Allesina S, Rodrigo A, Bosch J (2012) Drivers of compartmentalization in a Mediterranean pollination network. Oikos 121:2001-2013. https://doi.org/10.111 1/j.1600-0706.2012.20279.x

Martos F, Munoz F, Pailler T, Kottke I, Gonneau C, Selosse MA (2012) The role of epiphytism in architecture and evolutionary constraint within mycorrhizal networks of tropical orchids. Mol Ecol 21:5098-5109. https://doi.org/10.1111/j.1365-294X.2012.05692 $\mathrm{x}$

Mello MAR, Marquitti FMD, Guimarães PR, Kalko EKV, Jordano P, de Aguiar MAM (2011) The modularity of seed dispersal: differences in structure and robustness between bat- and bird-fruit networks. Oecologia 167:131-140. https://doi.org/10.1007/s0044 2-011-1984-2

Memmott J, Waser NM, Price MV (2004) Tolerance of pollination networks to species extinctions. Proc R Soc London Ser B 271:2605-2611. https://doi.org/10.1098/rspb.2004.2909

Miadlikowska J, Kauff F, Hofstetter V, Fraker E, Grube M, Hafellner J, Reeb V, Hodkinson BP, Kukwa M, Lücking R, Hestmark G, Otalora MG, Rauhut A, Büdel B, Scheidegger C, Timdal E, Stenroos S, Brodo I, Perlmutter GB, Ertz D, Diederich P, Lendemer JC, May P, Schoch CL, Arnold AE, Gueidan C, Tripp E, Yahr $R$, Robertson C, Lutzoni F (2006) New insights into the classification and evolution of the Lecanoromycetes (Pezizomycotina, Ascomycota) from a phylogentic analysis of three ribosomal RNA and two protein-coding genes. Mycologia 98:1088-1103

Miadlikowska J, Kauff F, Högnabba F, Oliver JC, Molnár K, Fraker E, Gaya E, Hafellner J, Hofstetter V, Gueidan C, Otálora MA, Hodkinson B, Kukwa M, Lücking R, Björk C, Sipman HJ, Burgaz AR, Thell A, Passo A, Myllys L, Goward T, FernándezBrime S, Hestmark G, Lendemer J, Lumbsch HT, Schmull M, Schoch CL, Sérusiaux E, Maddison DR, Arnold AE, Lutzoni F, Stenroos S (2014) Multigene phylogenetic synthesis for the class Lecanoromycetes (Ascomycota): 1307 fungi representing 1139 infrageneric taxa, 312 genera and 66 families. Mol Phylogenet Evol 79:132-168

Montesinos-Navarro A, Segarra-Moragues JG, Valiente-Banuet A, Verdú M (2012) The network structure of plant-arbuscular mycorrhizal fungi. New Phytol 194:536-547. https://doi.org/1 0.1111/j.1469-8137.2011.04045.x

Muggia L, Vancurova L, Škaloud P, Peksa O, Wedin M, Grube M (2013) The symbiotic playground of lichen thalli: a highly flexible photobiont association in rock-inhabiting lichens. FEMS Microbiol Ecol 85:313-323. https://doi.org/10.1111/1574-6941.12120

Muggia L, Pérez-Ortega S, Kopun T, Zellnig G, Grube M (2014) Photobiont selectivity leads to ecological tolerance and evolutionary divergence in a polymorphic complex of lichenized fungi. Ann Bot 114:463-475. https://doi.org/10.1093/aob/mcu146

Nadyeina O, Dymytrova L, Naumovych A, Postoyalkin S, Werth S, Cheenacharoen S, Scheidgger C (2014) Microclimatic differentiation of gene pools in the Lobaria pulmonaria symbiosis in a primeval forest landscape. Mol Ecol 23:5164-5178. https://doi. org/10.1111/mec.12928

Nash TH (2008) Lichen biology. Cambridge University Press, New York

Nielsen A, Bascompte J (2007) Ecological networks, nestedness and sampling effort. J Ecol 95:1134-1141. https://doi.org/10.111 1/j.1365-2745.2007.01271.x

Nourani Y, Andresen B (1999) A comparison of simulated annealing cooling strategies. J Phys A 31:8373-8385. https://doi. org/10.1088/0305-4470/31/41/011

O'Brien HE, Miadlikowska J, Lutzoni F (2005) Assessing host specialization in symbiotic cyanobacteria associated with four closely related species of the lichen fungus Peltigera. Eur J Phycol 40:363-378. https://doi.org/10.1080/09670260500342647

O'Brien HE, Miadlikowska J, Lutzoni F (2009) Assessing reproductive isolation in highly diverse communities of the lichen-forming fungal genus Peltigera. Evolution (N Y) 63:2076-2086. https:// doi.org/10.1111/j.1558-5646.2009.00685.x

O'Brien HE, Miadlikowska J, Lutzoni F (2013) Assessing population structure and host specialization in lichenized cyanobacteria. New Phytol 198:557-566. https://doi.org/10.1111/nph.12165

Oksanen J, Blanchet FG, Friendly M, Kindt R, Legendre P, McGlinn D, Minchin PR, O'Hara RB, Simpson GL, Solymos P, Stevens MH, Szoecs E, Wagner H (2017). vegan: Community Ecology Package. R package version 2.4-5. https://CRAN.R-project.org/ package $=$ vegan

Olesen JM, Bascompte J, Dupont YL, Jordano P (2007) The modularity of pollination networks. Proc Natl Acad Sci USA 104:1989119896. https://doi.org/10.1073/pnas.0706375104

Otálora MAG, Martínez I, O’Brien H, Molina MC, Aragon G, Lutzoni F (2010) Multiple origins of high reciprocal symbiotic specificity at an intercontinental spatial scale among gelatinous lichens (Collemataceae, Lecanoromycetes). Mol Phyl Evol 56:10891095. https://doi.org/10.1016/j.ympev.2010.05.013

Otálora MA, Salvador C, Martínez I, Aragón G (2013) Does the reproductive strategy affect the transmission and genetic diversity of bionts in cyanolichens? A case study using two closely related species. Microb Ecol 65(2):517-530

Ovaskainen O, Hottola J, Shtonen J (2010) Modeling species co-occurrence by multivariate logistic regression generates new hypotheses on fungal interactions. Ecology 91:2514-2521. https://doi. org/10.1890/10-0173.1

Ovaskainen O, Tikhonov G, Norberg A, Blanchet FG, Duan L, Dunson D, Roslin T, Abrego N (2017) How to make more out of community data? A conceptual framework and its implementation as models and software. Ecol Lett 20:561-576. https://doi. org/10.1111/ele.12757

Peksa O, Škaloud P (2011) Do photobionts influence the ecology of lichens? A case study of environmental preferences in symbiotic green alga Asterochloris (Trebouxiophyceae). Mol Ecol 20:3936-3948. https://doi.org/10.1111/j.1365-294X.2011.05168 .x 
Piercey-Normore M (2009) Vegetatively reproducing fungi in three genera of the Parmeliaceae share divergent algal partners. Bryologist 112:773-785. https://doi.org/10.1639/0007-2745-112.4.773

Pimm SL, Lawton JH (1980) Are food webs divided into compartements? J Anim Ecol 49:879-898. https://doi.org/10.2307/4233

Plett JM, Daguerre Y, Wittulsky S, Vayssières A, Deveau A, Melton SJ, Kohler A, Morrell-Falvey JL, Brun A, Veneault-Fourrey C, Martin F (2014) Effector MiSSP7 of the mutualistic fungus Laccaria bicolor stabilizes the Populus JAZ6 protein and represses jasmonic acid (JA) responsive genes. Proc Natl Acad Sci USA 111:8299-8304. https://doi.org/10.1073/pnas.1322671111

Podani J, Schmera D (2011) A new conceptual and methodological framework for exploring and explaining pattern in presenceabsence data. Oikos 120:1625-1638. https://doi.org/10.111 1/j.1600-0706.2011.19451.x

Podani J, Schmera D (2012) A comparative evaluation of pairwise nestedness measures. Ecography (Cop) 35:889-900. https://doi. org/10.1111/j.1600-0587.2011.07319.x

Podani J, Ricotta C, Schmera D (2013) A general framework for analyzing beta diversity, nestedness and related community-level phenomena based on abundance data. Ecol Complex 15:52-61. https://doi.org/10.1016/j.ecocom.2013.03.002

Porter SS, Simms EL (2014) Selection for cheating across disparate environments in the legume-rhizobium mutualism. Ecol Lett 17:1121-1129

Poulin R (1998) Large-scale patterns of host use by parasites of freshwater fishes. Ecol Lett 1:118-128. https://doi.org/10.104 6/j.1461-0248.1998.00022.x

Poulin R, Guégan JF (2000) Nestedness, anti-nestedness, and the relationship between prevalence and intensity in ectoparasite assemblages of marine fish: a spatial model of species coexistence. Int J Parasitol 30:1147-1152. https://doi.org/10.1016/S0020 -7519(00)00102-8

Price PW (1980) Evolutionary biology of parasites. Princeton University Press, Princeton

Reid NM, Carstens BC (2012) Phylogenetic estimation error can decrease the accuracy of species delimitation: a Bayesian implementation of the general mixed Yule-coalescent model. BMC Evol Biol 12:196. https://doi.org/10.1186/1471-2148-12-196

Rezende EL, Lavabre JE, Guimaraes PR Jr, Jordano P, Bascompte J (2007) Non-random coextinctions in phylogenetically structured mutualistic networks. Nature 448:925. https://doi.org/10.1038/ nature 05956

Rikkinen J (2003) Ecological and evolutionary role of photobiontmediated guilds in lichens. Symbiosis 34:99-110

Rikkinen J, Oksanen I, Lohtander K (2002) Lichen guilds share related cyanobacterial symbionts. Science 297(5580):357

Rivera-Hutinel A, Bustamante RO, Marín VH, Medel R (2012) Effects of sampling completeness on the structure of plantpollinator networks. Ecology 93:1593-1603. https://doi. org/10.1890/11-1803.1

Stamatakis A (2006) RAxML-VI-HPC: maximum likelihood-based phylogenetic analyses with thousands of taxa and mixed models. Bioinformatics 22:2688-2690. https://doi.org/10.1093/bioin formatics/btl446

Stamatakis A, Hoover P, Rougemont J (2008) A rapid bootstrap algorithm for the RAxML Web servers. Syst Biol 57:758-771. https ://doi.org/10.1080/10635150802429642

Stang M, Klinkhamer PGL, van der Meijden E (2007) Asymmetric specialization and extinction risk in plant-flower visitor webs: a matter of morphology or abundance? Oecologia 151:442-453. https://doi.org/10.1007/s00442-006-0585-y

Stang M, Klinkhamer PG, Waser NM, Stang I, van der Meijden E (2009) Size-specific interaction patterns and size matching in a plant-pollinator interaction web. Ann Bot 103:1459-1469. https ://doi.org/10.1093/aob/mcp027

Steidinger BS, Bever JD (2014) The coexistence of hosts with different abilities to discriminate against cheater partners: an evolutionary game-theory approach. Am Nat 183:762-770. https://doi. org/10.1086/675859

Stenroos S, Högnabba F, Myllys L, Hyvonen J, Thell A (2006) High selectivity in symbiotic associations of lichenized ascomycetes and cyanobacteria. Cladistics 22:230-238. https://doi.org/10.11 11/j.1096-0031.2006.00101.x

Strauss S, Irwin R (2004) Ecological and evolutionary consequences of multispecies plant-animal interactions. Annu Rev Ecol Evol Syst 35:435-466. https://doi.org/10.1146/annurev.ecolsys.35.11220 2.130215

Swarts ND, Sinclair EA, Francis A, Dixon KW (2010) Ecological specialization in mycorrhizal symbiosis leads to rarity in an endangered orchid. Mol Ecol 19:3226-3242. https://doi.org/10.1111/ j.1365-294X.2010.04736.x

Thébault E, Fontaine C (2010) Stability of ecological communities and the architecture of mutualistic and trophic networks. Science 329(80):853-856. https://doi.org/10.1126/science.1188321

Thompson JN (2009) The coevolving web of life. Am Nat 173:125140. https://doi.org/10.1086/595752

Toju H, Guimarães PR, Olesen JM, Thompson JN (2014) Assembly of complex plant-fungus networks. Nat Commun 5:5273. https ://doi.org/10.1038/ncomms6273

Torrecillas E, del Mar Alguacil M, Roldán A, Díaz G, MontesinosNavarro A, Torres MP (2014) Modularity reveals the tendency of arbuscular mycorrhizal fungi to interact differently with generalist and specialist plant species in gypsum soils. Appl Environ Microbiol 80:5457-5466. https://doi.org/10.1128/AEM.01358 $-14$

Ulanowicz RE (1986) Growth and development: ecosystems phenomenology. Springer, New York

Ulanowicz RE (1997) Ecology: the ascendant perspective. Columbia University Press, New York

Ulanowicz RE, Kemp WM (1979) Toward canonical trophic aggregations. Am Nat 114:871-883. https://doi.org/10.1086/283534

Ulrich W, Almeida-Neto M (2012) On the meanings of nestedness: back to the basics. Ecography (Cop) 35:865-871. https://doi.org /10.1111/j.1600-0587.2012.07671.x

Vázquez DP, Aizen MA (2004) Asymmetric specialization: a pervasive feature of plant-pollinator interactions. Ecology 85:1251-1257. https://doi.org/10.1890/03-3112

Vázquez DP, Poulin R, Krasnov BR, Shenbrot GI (2005) Species abundance and the distribution of specialization in host-parasite interaction networks. J Anim Ecol 74:946-955. https://doi.org/1 0.1111/j.1365-2656.2005.00992.x

Vázquez DP, Melián CJ, Williams NM, Blüthgen N, Krasnov BR, Poulin R (2007) Species abundance and asymmetric interaction strength in ecological networks. Oikos 116:1120-1127. https:// doi.org/10.1111/j.2007.0030-1299.15828.x

Vellend M (2016) The theory of ecological communities. Princeton University Press, Princeton

Wardhaugh CW, Edwards W, Stork NE (2015) The specialization and structure of antagonistic and mutualistic networks of beetles on rainforest canopy trees. Biol J Linn Soc 114:287-295. https:// doi.org/10.1111/bij.12430

Wedin M, Döring H, Gilenstam G (2004) Saprotrophy and lichenization as options for the same fungal species on different substrata: environmental plasticity and fungal lifestyles in the Stictis-Conotrema complex. New Phytol 164:459-465. https://doi.org/10.11 $11 / \mathrm{j} .1469-8137.2004 .01198 . x$ 
Wilson DS, Yoshimura J (1994) On the coexistence of specialists and generalists. Am Nat 144:692-707. https://doi.org/10.2307/26788 32

Wirtz N, Lumbsch HT, Green TGA, Türk R, Pintado A, Sancho L, Schroeter B (2003) Lichen fungi have low cyanobiont selectivity in maritime Antarctica. New Phytol 160:177-183. https://doi.org /10.1046/j.1469-8137.2003.00859.x

Yahr R, Vilgalys R, Depriest PT (2004) Strong fungal specificity and selectivity for algal symbionts in Florida scrub Cladonia lichens. Mol Ecol 13:3367-3378. https://doi.org/10.1111/j.1365294X.2004.02350.x

Yahr R, Vilgalys R, Depriest PT (2006) Geographic variation in algal partners of Cladonia subtenuis (Cladoniaceae) highlights the dynamic nature of a lichen symbiosis. New Phytol 171(4):847-860

Yang Z, Rannala B (2010) Bayesian species delimitation using multilocus sequence data. Proc Natl Acad Sci USA 107:9264-9269. https://doi.org/10.1073/pnas.0913022107

Zhang J, Kapli P, Pavlidis P, Stamatakis A (2013) A general species delimitation method with applications to phylogenetic placements. Bioinformatics 29:2869-2876. https://doi.org/10.1093/ bioinformatics/btt499

Zúñiga C, Leiva D, Carú M, Orlando J (2017) Substrates of Peltigera lichens as a potential source of cyanobtionts. Microb Ecol 74(3):561-569. https://doi.org/10.1007/s00248-017-0969-z 